\title{
Parameter Estimation and Sensitivity Analysis of an Optimal Control Model for Capital Asset Management
}

\author{
Tolulope Latunde $\mathbb{D}^{1}$ and Olabode Matthias Bamigbola ${ }^{2}$ \\ ${ }^{1}$ Department of Mathematics, P.M.B 373, Federal University Oye-Ekiti, Oye-Ekiti, Nigeria \\ ${ }^{2}$ Department of Mathematics, P.M.B 1515, University of Ilorin, Ilorin, Nigeria \\ Correspondence should be addressed to Tolulope Latunde; tolulope.latunde@fuoye.edu.ng
}

Received 23 May 2018; Accepted 16 July 2018; Published 12 August 2018

Academic Editor: Katsuhiro Honda

Copyright (c) 2018 Tolulope Latunde and Olabode Matthias Bamigbola. This is an open access article distributed under the Creative Commons Attribution License, which permits unrestricted use, distribution, and reproduction in any medium, provided the original work is properly cited.

\begin{abstract}
Optimal control is a very significant field of modern control theory which has been applied in many areas like medicine, science, and finance. This work is based on realization of asset values as a benefit of asset management where a capital asset management problem is modelled and expressed mathematically from the perspective of an investor whose income is generated by return and capital gains on investments with price and return on assets assumed to satisfy uncertainty process. This results in an optimal control model based on uncertainty theory which relates two or more parameters that measures the condition or state of individual's investments. These parameters enable us to know the condition of risk involved in asset management and how to maintain and manage the assets in order to maximize expected present value of the utility of asset and minimize the risk involved to aid capital investment decision-making. Parameter sensitivity analysis is an approach given to a model so as to define significance of the factors related to the model where the whole parameter space is fully described. However, the model is applied to a real-life problem of capital asset management to deal with debt crisis of a nation's economy and the sensitivity analysis to determine the effects of the input factors on the model is investigated such that relative significance and sensitivity of each parameter on the model results are presented using parameter estimations. Finally the optimal control decision policy is obtained and discussed.
\end{abstract}

\section{Introduction}

Capital assets are significant pieces of property such as plants and machinery, land and buildings, vehicles, and estates. For businesses, they have useful life usually longer than a year. Risky capital assets are the capital assets that carry a degree of risk, that is, assets that have a significant degree of price volatility, depreciation, hazards, inflation, or liability.

The Institute of Asset Management (IAM) explains that asset management which is the planned action of an organization to acknowledge value from assets is no more new; people and organizations have been managing assets for a large number of year. What has changed, however, is the cumulative recognition of what good asset management involves, the optimizing of costs, risk performance, resources and benefits over a given time, and likewise considering that risks are inherent in all decision-making. The typical priorities of asset management are keeping stakeholders happy, substantial returns on investment compliance and sustainability, systems performance, cost and risk optimization, and efficiency and effectiveness of an asset's life cycle.

In dealing with real-life or physical problems, mathematical modelling is always of great advantage because of its power to predict system behaviour and a clear insight of the important inputs and outputs. Mathematical models are of various forms such as deterministic, stochastic, fuzzy, and uncertain forms, Mazur [1].

However, there is a need to model problems arising from the successful management of capital assets using the following essential methodology: identifying the needs of customers, regulators, or investors; designing or formulating the model; utilizing and maintaining the model; and managing residual liabilities. Thus, following the methodology, an uncertain optimal control model of capital assets is developed to tackle some problems that arise in the optimization of capital assets such that the expected net worth is maximized 
and capital growth is attained while risk is minimized. Here, maximizing the expected net worth of the investment is considered as the objective of the optimal control while the present net worth is considered as the constraint which is expressed as asset-liability problem.

In most practical problems, we are interested not only in the optimal solution of the control problem but also in how the solution changes when the parameters of the problem change. The change in the parameters may be discrete or continuous. The study of the effect of discrete parameter changes on the optimal solution is called the sensitivity analysis while that of the continuous changes is termed the parametric programming, Rao [2].

Parameter sensitivity analysis is an essential method for examining mathematical models of a real-life problem. A detailed parameter sensitivity analysis gives a broad set of predictions that show how changes in a model parameter affect relevant model outputs. A parameter is a characteristic, a measurable factor, a feature that can help in defining a particular system. Therefore, the effects of changes in the parameters of a model are determined by solving the model and comparing the results with respect to changes made with parameters in the model's configuration space.

From existing works, it is noticed that Merton [3], Zhu [4], and Deng and Zhu [5] examined the selection riskfree asset and risk asset together in the formulation of the models. Meanwhile, Stein [6] examined the selection of risky assets only with stochastic optimal control approach without considering depreciation and taxation as input factors. Consequently, in this research work, uncertainty theory is utilized in the model formulation whereby the selection of risky assets only is examined; thus, depreciation and taxation are considered as input factors in the formulation of the model. Furthermore, the relative significance of each parameter of the model is determined in order to describe the ability to move the model around the assets' entire configuration space with minimum execution time.

\section{Literature Review}

Real-life problems are often modelled as mathematical expressions which sometimes include parameters. Examples abound in electrical engineering, finance, economics, and medical sciences, to name a few. A model is defined as a simplified representation of certain aspects of real-life system. A mathematical model is a model created using mathematical concepts such as functions and equations. When mathematical models are created, it is assumed that there is a movement from real world into the theoretical world of mathematical concepts, where the model is built. The model is then manipulated using mathematical or computer aided techniques. Finally the real world is reentered, which is then translated into useful solution to the real problem which implies that the start and end are in the real world, Edward and Hamson [7]. Thus, several researchers have worked on the applications of mathematical modelling into solving reallife situations such as in mathematical modelling, a useful tool for STI control policy, Ashleigh et al. [8], mathematical modelling application to corrosion in a petroleum industry,
Oyelami and Asere [9], dynamic modelling of a wind turbine with doubly fed induction generator, Poller and Achilles [10], and a mathematical theory to model complex socioeconomical systems by functional subsystems representation, Giulia et al. [11]. As such, much emphasis has been on the operational aspect rather than the economical aspect of mathematical modelling. However, several researchers have also worked on the sensitivity analysis of the modelling parameters used in various types of models. Rosa and Torres [12] carried out a sensitivity and cost-effectiveness analysis on periodic epidemic model, Papageorgiou et al. [13] carried out sensitivity analysis for optimal control problems which is governed by nonlinear evolution inclusion, Fordor et al. (2010) worked on parameter sensitivity analysis of a synchronous generator, Zivarian (2002) also worked on sensitivity analysis of a nonlinear lumped parameter model of HIV infection dynamics, Kathirgamanathan and Neitzart [14] worked on optimal control parameter estimation in Aluminium extrusion for given product characteristics, Guo et al. [15] worked on the performance evaluation and parameter sensitivity of energyharvesting shock absorbers on different vehicles, Christopher and Fathalla [16] worked on sensitivity analysis of parameters in modelling with delay-differential equations, Burns et al. [17] worked on sensitivity analysis and parameter estimation for a model Chlamydia Trachomatis infection, and Bastidas et al. [18] worked on parameter sensitivity and uncertain analysis for a storm surge and wave model to mention but a few. The main concern in mathematical modelling is to establish relationships between factors but this also almost invariably involves parameters. Parameters are quantified factors that have constant values for a particular problem but can change from problem to problem, Edward and Hamson [7]. In general, a model can be of some use in predicting general behaviour in a descriptive fashion. To use the model in a practical way, we must solve for the numerical values of the parameters from given data. The use of data to obtain parameter values relevant to a particular application of the model is frequently called or sometimes the model. The common methods of obtaining the parameter values are graphical, statistical (usually involving least-squares estimation), and mathematical (usually requiring the solution of linear or nonlinear equations) methods. Parameters are used to identify characteristics, features, and measurable factors that can help in defining a specific system. They are essential elements to take into consideration for the evaluation of an event, a project, or any situation.

The optimization of asset management is influenced by a large number of processes, which has been modelled by many researchers with various mathematical methods based on different theories. Tunjo and Zoran [19] worked on financial structure optimization using a goal programming approach which proposes a new methodology for solving multiobjective fractional linear programming problems using Taylor's series formula, Xiaoxia [20] worked on portfolio selection with a new definition of risk in which a new type of model was proposed based on his new definition, and Schyns [21] worked on financial data and portfolio optimization problems where he deals with an extension of Merkowitz model and takes into account some of the side-constraints faced 
TABLE 1: Sensitivity classification of modelling parameters.

\begin{tabular}{lcc}
\hline Class & Relative significance & Percentage change \\
\hline Insensitive parameter & its influence on the model's accuracy is not critical & $0-0.9 \%$ \\
Sensitive parameter & its influence on the model accuracy is significant & $1-9.9 \%$ \\
Very sensitive parameter & its influence on the model accuracy is very significant & $10-19.9 \%$ \\
Extremely sensitive parameter & its influence on the model accuracy is very critical & $>20 \%$ \\
\hline
\end{tabular}

by a decision-maker when compromising an investment portfolio. There are many approaches which researchers have used in optimizing the asset management and measure risk. These are not limited to fuzzy approach, log robust approach, heuristic approach, stochastic approach, and uncertainty approach.

In most practical problems, the interest is not just in the solution of the problem, but also in how the solution changes when the parameters of the problem change. Parameter sensitivity analysis is thus used to decide how sensitive the results of propagation of a parameter by varying the estimation of the parameter in a model. A mathematical model comprises parameters, in which the more the parameters existing in the model, the higher the dimension of the model and the more complex to solve. Thus, the sensitivity of parameters makes it easier in determining the relative significance of each parameter, thus modifying the model by reducing the model's dimension which reduces the complexity.

The optimal control model of risky capital assets based on uncertainty theory, however, requires over 15 input parameters. These parameters help in quantifying some factors utilized in the model. It is therefore necessary to survey available values for these input parameters and ascertain the sensitivity of the model to changes in every one of the parameters.

The sensitivity of parameters helps in classifying modelling parameters into different types on the relative significance of each parameter related to a model. The classification can be done using the information in Table 1.

\section{Mathematical Description of the Model}

Capital asset management manages the significant pieces of investment properties owned by an investor that is aimed at generating value over a given time. Capital assets constitute the productive base of an organization

Managing the capital assets is therefore expatiated with the view of its objectives. Examining the objectives below demonstrates that the advantages of one often comes at the expense of the benefits of another. If an investor desires growth, for example, he or she should frequently sacrifice income or safety. In this manner, most portfolios will be piloted by one preeminent goal, with all other potential objectives involving less critical weight in the overall scheme.

Picking a single strategic objective and assigning weightings to all other conceivable objectives is a procedure that relies on such factors as the investor's personality, his or her stage of life, marital status, family situation, etc. Out of the huge number of possibilities out there, each investor is certain to find an appropriate mix of investment opportunities. You require just to be concerned with spending the appropriate measure of time and effort in discovering, studying, and deciding on the opportunities that suit your objectives

The basic goals of capital asset management are safety, income, and growth of capital while tax minimization and marketability/liquidity are classified as secondary objectives of capital asset management.

Capital asset management is mainly based on decisionmaking and the understanding of probable asset degradation and trading-off capital investments, maintenance costs, risks, and other uncertainties to optimize decisions made by investors. In considering the issue involved generally in risky capital assets, the following problem statement is considered.

An individual invests his wealth in capital asset, $A(t)$, of a large business for time, $t$, ranging from $t_{0}$ to $t_{n}$. Suppose he starts with a known initial net worth $X_{0}(t)$. At time $t$, what fraction of his net worth, $\psi$, must he choose to use on capital asset and what fraction of his net worth, $\tau$, must he choose to be incurred on liability of the business such that the net worth and expected present value of the utility of asset, $J(X)$, are maximized?

In order to model indeterminacy, we have two mathematical theories which are probability theory and uncertainty theory. However, in addressing issues raised above, the experiences from investors or capital assets managers are not sufficient and reliable enough to rationally deal with belief degrees, thus making the uncertainty theory a good approach to the problem. Furthermore, uncertainty theory is briefly discussed and some parameters used in the model formulation are presented and described in Table 2.

3.1. Uncertainty Theory. Uncertainty theory is an area of mathematics for modelling belief degrees founded by Liu in 2007. This theory is based on a few concepts which may be alluded to Liu (2016). For easy elucidation, a portion of the concepts are given below.

Let $\Gamma$ be a nonempty set and $L$ a $\sigma$-algebra over $\Gamma$ such that $(\Gamma, L)$ is a measurable space such that each element $\Lambda \in L$ is called an event. Thus we have the following definitions.

Definition 1 ([22]). A set function $M$ defined on the $\sigma$ algebra over $L$ is called an uncertain measure if it satisfies the following axioms:

Axiom 1 (normality axiom). $M\{\Lambda\}=1$ for the universal set $\Gamma$.

Axiom 2 (duality axiom). $M\{\Lambda\}+M\left\{\Lambda^{c}\right\}=1$ for any event $\Lambda$.

Axiom 3 (subadditivity axiom). For every countable sequence of events, $\Lambda_{1}, \Lambda_{2}, \cdots$, we have

$$
M\left\{\bigcup_{i=1}^{\infty} \Lambda_{i}\right\} \leq \sum_{i=1}^{\infty} M\left\{\Lambda_{i}\right\}
$$


TABLE 2: Definition of parameters to the model.

\begin{tabular}{lc}
\hline Parameter & Description \\
\hline$X(t)$ & Net worth at time (state variable) $t$ \\
$\tau(t)$ & Liability ratio (control) at time $t, \tau \in \mathfrak{R}$ \\
$\sigma_{r}(t)$ & Ciffusion volatility of liability (with variance $\sigma_{r}^{2}$ per unit time) \\
$\psi(t)$ & Capital asset ratio (control) $\psi \in \mathfrak{R}$ \\
$\sigma_{b}(t)$ & Diffusion volatility of asset (with variance $\sigma_{b}^{2}$ per unit time) \\
$\kappa(t)$ & Capital gain on asset due to inflation at time $t$ \\
$\sigma_{p}(t)$ & Diffusion volatility on asset price (with variance $\sigma_{p}^{2}$ per unit time) \\
$\beta(t)$ & Mean rate of return on asset at time $t$ \\
$\omega(\mathrm{t})$ & Mean interest rate of liability time $t$ \\
$C(t)$ & Liu canonical process at time $t$ \\
$\mu(t)$ & Consumption level at time $t$ \\
$j(t)$ & Tax ratio at time $t$ \\
$g(t)$ & Depreciation ratio at time $t$ \\
$s(t)$ & Asset supplies ratio at time $t$ \\
$\eta$ & subjective discount rate, e.g., $A /(\eta+1)=$ Presentvalue \\
$\lambda$ & degree of relative risk, where $(1-\lambda)$ is the risk aversion \\
$U$ & Utility function \\
\hline
\end{tabular}

Axiom 4 (product axiom). Let $\left(\Gamma_{k}, L_{k}, M_{k}\right)$ be uncertainty spaces for $k=1,2, \cdots$. The product uncertain measure $M$ is an uncertain measure satisfying

$$
M\left\{\prod_{k=1}^{\infty} \Lambda_{k}\right\}=\min _{1 \leq k \leq \infty} M_{k}\left\{\Lambda_{k}\right\}
$$

where $\Lambda_{k}$ are arbitrarily chosen events from $L_{k}$ for $k=$ $1,2, \cdots$, respectively.

Definition 2 (Liu 2009). An uncertain process $C_{\sigma}$ is said to be a canonical Liu process if

(i) $C_{0}=0$ and almost all sample paths are Lipschitz continuous,

(ii) $C_{\sigma}$ has stationary and independent increments,

(iii) every increment $C_{s+\sigma}-C_{s}$ is a normal uncertain variable with expected value 0 and variance $\sigma^{2}$. The uncertainty distribution of $C_{\sigma}$ is

$$
\Phi_{\sigma}(x)=\left[1+\exp \left(\frac{-\pi x}{\sqrt{3} \sigma}\right)\right]^{-1}, \quad x \in \mathfrak{R}
$$

and the inverse distribution is

$$
\Phi_{\sigma}^{-1}(y)=\frac{\sigma \sqrt{3}}{\pi} \ln \frac{y}{1-y}, \quad y \in \Re
$$

Definition 3 ([22]). Let $\xi$ be an uncertain variable. Then the expected value of $\xi$ is defined by

$$
E[\xi]=\int_{0}^{+\infty} M\{\xi \geq x\} d x-\int_{-\infty}^{0} M\{\xi \leq x\} d x
$$

provided that at least one of the two integrals is finite
Definition 4 (Liu 2008). An uncertain process $X_{t}$ is said to have independent increments if

$$
X_{t_{1}}-X_{t_{0}}, X_{t_{2}}-X_{t_{1}}, \cdots, X_{t_{k}}-X_{t_{k-1}}
$$

are independent uncertain variables where $t_{1}, t_{2}, \cdots, t_{k}$ are any times with $t_{0}<t_{1}<\cdots<t_{k}$

That is, an independent increment process means that its increments are independent uncertain variables whenever the time intervals do not overlap. It is noted that the increments are also independent of the initial state.

Definition 5 (Liu 2008). Suppose $C_{t}$ is a canonical Liu process, and $f$ and $g$ are two functions. Then

$$
d X_{t}=f\left(t, X_{t}\right) d t+g\left(t, X_{t}\right) d C_{t}
$$

is called an uncertain differential equation. A solution is a Liu process $X_{t}$ that satisfies (3) and (4) identically in $t$.

Definition 6 (Liu 2008). Let $X_{t}$ be an uncertain process. Then, for each $\gamma \in \Gamma$, the function $X_{t}(\gamma)$ is called a sample path of $X_{t}$.

Definition 7 (Liu 2016). An uncertain process $X_{t}$ is said to be sample-continuous if almost all sample paths are continuous functions with respect to time $t$.

Therefore, a dynamic optimization model of the expected present value of asset over a given life cycle, formulated by Latunde and Bamigbola [23], is herein presented following the study of portfolio selection by Merton [3] and uncertainty theory by Liu [22]. It is assumed that the objective of the asset management is to pick the optimal usage and policies of asset allocation for optimizing a value function which discounts exponentially future uncertain values with 
Hyperbolic Absolute Risk Aversion (HARA) utility function over a given time frame and net worth of tangible assets as the state variable.

The risky asset is assumed to earn an uncertain return and an uncertain gain with mean rate of return and capital gain. Furthermore, we express the change in liability as sum of liability service with an assumption of uncertainty, consumption, investment and net foreign supply, less taxation, depreciation, and revenue over a period of time. Thus, we have

$$
J(X)=\max _{\psi} E_{C}\left[\int_{t_{0}}^{t_{n}} \frac{1}{\lambda} e^{-\eta t}(\psi X(t))^{\lambda} d t\right]
$$

subject to

$$
\begin{aligned}
d X(t) & \\
= & {[(\kappa+\beta) \psi-(\omega(\psi-1)+\mu+s-j-g)] X(t) d t } \\
& +\left[\psi \sigma_{p}+\psi \sigma_{b}-\sigma_{r}(\psi-1)\right] X(t) d C(t)
\end{aligned}
$$

\section{Analysis of the Model}

Here, the model is analysed using real-life data in order to provide control policies in solving the problem of the study case and also to show the satisfaction of optimality criteria. Likewise, the sensitivity investigation of the model is done aiming to determine the relative significance of a few of the parameters on the model results.

\subsection{Application of Risky Capital Assets Model to Debt Crisis.} Debt simply means a sum of money that is owed or due. In international finance, debt is categorized as an example of liability. Debt is as old as economy. It was the principal type of trade (barter system) recorded in mankind's history and existed around 2,900 years before the development of coinage. Today there are numerous cases of moneylenders of fiscal debt that incorporate countries, banks, credit card companies, organizations, individuals, and so forth, who in numerous cases subject their borrowers to legally binding terms that assign the sum and timing of reimbursements of the obligation and that habitually incorporate the instalment of principal and interest.

National debt (also known as government debt, public debt, and sovereign debt) alludes to the total amount owed by the federal government of the country. This may also refer to the sum total of external/foreign and internal/domestic (state and local government) debts.

Debt crisis is the general term used to depict a large public debt relative to tax revenues. This simply means the blend of accumulated debt stock and problems in servicing debt.

However, public debt which is denominated in either internal or external currency must be repaid at maturity in the case of short term debt or serviced regularly in the case of long term debt. In order to accomplish that and prevent recurrence of debt crisis, an uncertainty optimal control approach is presented such that there exist some sources of uncertainty when dealing with debt: return on capital, price of capital, and interest rate of liability (debt) such that they are correlated.
4.2. Case Study. Nigeria is known as the largest country in West Africa in terms of economy. Her debt crisis was selected as a case study to the model of capital asset management because there are available data that correspond closely to the model.

Early 1980s, the difficulty in debt servicing started in Nigeria when the foreign exchange earnings rose as a result of collapse of prices in the international oil market and external obligations began to be procured indiscriminately. Since then, the GDP growth rate and Gross Fixed Capital Formation (GFCF) rate or investment rate and export earnings have been affected thus resulting in a drastic rise of interest rates $r(t)$ leading to difficulties in servicing debt, thus, resulting in a declining economic growth and development of the nation. GDP is the monetary value of all the finished goods and services produced within a country's borders in a specific time period; meanwhile the GFCF (formerly gross domestic fixed investment) includes land improvements (fences, ditches, drains, and so on); plant, machinery, and equipment purchases; and the construction of roads, railways, and the like, including schools, offices, hospitals, private residential dwellings, and commercial and industrial buildings of the nation.

Despite the Paris Club debt forgiveness in October 2005 where Nigeria and the Paris Club announced a final agreement for debt relief worth 18 billion dollars and an overall reduction of Nigeria's debt stock by 30 billion dollars, the deal was completed on April 21, 2006, when Nigeria made its final payment and its books were cleared of any Paris Club debt. It was expected to solve the nation's debt crisis and accelerate the growth and development of the economy. Rather, it did not put an end to the nation's debt crisis. Thus, it is necessary to be aware of, predict, and control the period of debt crisis as a signal warning.

Utilizing the model in international finance, we take the revenue to be the Gross Domestic Product of a nation (GDP) or value added, the risky capital asset as the capital investment or the Gross Fixed Capital Formation, Consumption as Household and Government Consumption, and Depreciation as the Consumption of Fixed capital. We also take debt as a study case of liability to be considered.

In order to examine the debt crisis in Nigeria and propose a warning signal, we use data that are available after the Paris debt forgiveness in 2006. Thus, Tables 2 and 3 represent the base parameter set for the case study obtained from the records of National Bureau of Statistics (http://nigerianstat.gov.ng/) and Debt Management Office (https://www.dmo.gov.ng/), Nigeria, at end of each year. Note that the CBN Official Exchange rate of USD at 31st December of each year is used.

Table 4 is computed from Table 3.

Measurements. The measurements considered in obtaining data in Tables 2-4 are described below.

All the values of parameters are measured in Billion US Dollars except the following parameters: $C(t)$ measures the uncertainty process which exists in the interval $0<C(t)<1$; $\lambda$ is used to measure risk which exists in the interval $0<\lambda<$ 1 ; and $\eta$ measures discount rate which exists in the interval 
TABLE 3: Nigeria net worth profile.

\begin{tabular}{ccccccccc}
\hline Year & GDP & Debt & GFCF & Net worth & Consumption & Indirect Tax & Depreciation & Supplies \\
\hline 2007 & 166.451 & 22.330 & 15.396 & -6.934 & 149.152 & 2.553 & 3.738 & 3.089 \\
2008 & 208.065 & 21.399 & 17.318 & -4.081 & 161.035 & 3.436 & 3.853 \\
2009 & 169.481 & 25.817 & 20.487 & -5.330 & 147.601 & 3.180 & 2.952 \\
2010 & 369.062 & 40.100 & 61.099 & 21.860 & 293.507 & 5.623 & 16.079 \\
2011 & 411.744 & 47.898 & 63.960 & 16.062 & 323.540 & 4.516 & 18.815 \\
2012 & 460.953 & 48.496 & 65.283 & 16.787 & 348.597 & 5.686 & 24.260 \\
2013 & 514.966 & 64.510 & 72.964 & 8.454 & 453.699 & 7.929 & 38.719 \\
2014 & 568.499 & 67.726 & 85.737 & 18.011 & 464.696 & 6.857 & 23.857 \\
2015 & 481.066 & 65.429 & 71.329 & 5.900 & 417.560 & 5.362 & 25.210 \\
2016 & 405.083 & 57.392 & 73.261 & 15.869 & 206.414 & 3.188 & 23.272 \\
\hline
\end{tabular}

Source:

Columns 1 and 3: The World Bank (https://data.worldbank.org/indicator).

Column 2: Debt Management Office of Nigeria (https://www.dmo.gov.ng/).

Columns 5, 6, 7, 8, and 9: National Bureau of Statistics (http://nigerianstat.gov.ng/).

TABle 4: Parameters for the Nigeria net worth profile.

\begin{tabular}{cccccccccccc}
\hline Year & $\boldsymbol{\kappa}$ & $\boldsymbol{\beta}$ & $\boldsymbol{\omega}$ & $\boldsymbol{\sigma}_{\boldsymbol{p}}$ & $\boldsymbol{\sigma}_{\boldsymbol{b}}$ & $\boldsymbol{\sigma}_{\boldsymbol{r}}$ & $\boldsymbol{\sigma}$ & $\boldsymbol{\mu}$ & $\mathbf{s}$ & $\mathbf{j}$ \\
\hline 2007 & -7.25 & -51.72 & -6.10 & -3.78 & -21.47 & -2.46 & -22.79 & -21.51 & -0.73 & -0.37 & -0.54 \\
2008 & -12.32 & -87.88 & -10.36 & -6.42 & -36.48 & -4.17 & -38.73 & -39.46 & -7.59 & -0.77 & -0.94 \\
2009 & -9.43 & -67.29 & -7.93 & -4.92 & -27.93 & -3.20 & -29.65 & -27.69 & 0.08 & -0.60 & -0.55 \\
2010 & 2.30 & 16.41 & 1.93 & 1.20 & 6.81 & 0.78 & 7.23 & 13.43 & 1.31 & 0.26 & 0.74 \\
2011 & 3.13 & 22.33 & 2.63 & 1.63 & 9.27 & 1.06 & 9.84 & 20.14 & 2.14 & 0.28 & 1.17 \\
2012 & 2.30 & 21.37 & 2.52 & 1.56 & 8.87 & 1.02 & 9.41 & 20.77 & 5.14 & 0.34 & 1.45 \\
2013 & 5.95 & 42.42 & 5.00 & 3.10 & 17.61 & 2.02 & 18.69 & 53.67 & 3.11 & 0.94 & 2.82 \\
2014 & 2.79 & 19.91 & 1.43 & 1.46 & 8.27 & 0.95 & 8.78 & 25.80 & 1.92 & 0.37 & 1.40 \\
2015 & 8.52 & 60.79 & 4.37 & 4.44 & 25.23 & 2.89 & 26.78 & 70.77 & 0.00 & 0.91 & 3.91 \\
2016 & 3.17 & 22.60 & 1.63 & 1.65 & 9.38 & 1.07 & 9.96 & 13.01 & -0.21 & 0.20 & 0.65 \\
\hline
\end{tabular}

$0<\eta<1$. The debt is calculated as the total debt of the nation by summing the external debt stock (federal government and state) and domestic debt (federal government and state) together. The net worth is also calculated by deducting the debt from the GFCF. The CBN Official Exchange rate of USD at 31st December of each year is used while current market prices from the national account are used in the computations.

4.3. Solution to the Model. Numerical solutions are presented via trapezoidal rule for the objective functional and Euler method and fourth-order Runge-Kutta method for solving uncertain differential equations due to its ability to yield more precise outcomes than other methods for the constraints, Yang and Shen [24].

Trapezoidal method is

$$
\begin{aligned}
\int_{a}^{b} f(x) d x & =\frac{h}{2}\left(f_{0}+2 f_{1}+2 f_{2}+\cdots+2 f_{n-1}+f_{n}\right) \\
& =h\left(\frac{f_{0}+f_{n}}{2}+\sum_{i=1}^{n-1} f_{i}\right),
\end{aligned}
$$

where $f\left(x_{k}\right) \equiv f_{k}$.
The Runge-Kutta method for solving uncertain differential equations was designed by Yang and Shen [24] with respect to the following definition and theorems.

Runge-Kutta method is an effective method for solving ordinary differential equations. The generally used RungeKutta formula is a fourth-order formula. Note that there is a variety of fourth-order schemes and, here, just one common structure is exhibited. For an ordinary differential equation with initial value $X_{0}$

$$
d X(t)=F(t, X(t)) d t .
$$

The scheme uses the following formula:

$$
X\left(t_{n+1}\right)=X\left(t_{n}\right)+\frac{1}{6}\left(k_{1}+2 k_{2}+2 k_{3}+k_{4}\right)
$$

where

$$
\begin{aligned}
& k_{1}=h F\left(t_{n}, X_{n}\right), \\
& k_{2}=h F\left(t_{n}+\frac{h}{2}, X_{n}+\frac{1}{2} k_{1}\right), \\
& k_{3}=h F\left(t_{n}+\frac{h}{2}, X_{n}+\frac{1}{2} k_{2}\right), \\
& k_{4}=h F\left(t_{n}+h, X_{n}+k_{3}\right)
\end{aligned}
$$


and $h$ is the step size which is assumed to be constant for all steps.

However, Yang and Shen [24] designed a Runge-Kutta method for uncertain differential equations as

$$
X_{i+1}^{\alpha}=X_{i}^{\alpha}+\frac{1}{6}\left(k_{1}+2 k_{2}+2 k_{3}+k_{4}\right)
$$

where

$$
\begin{aligned}
k_{1} & =h\left(f\left(t_{i}, X_{i}^{\alpha}\right)+\left|g\left(t_{i}, X_{i}^{\alpha}\right)\right| \Phi^{-1}(\alpha)\right), \\
k_{2} & =h\left(f\left(t_{i}+\frac{h}{2}, X_{i}^{\alpha}+\frac{1}{2} k_{1}\right)\right. \\
& \left.+\left|g\left(t_{i}+\frac{h}{2}, X_{i}^{\alpha}+\frac{1}{2} k_{1}\right)\right| \Phi^{-1}(\alpha)\right), \\
k_{3} & =h\left(f\left(t_{i}+\frac{h}{2}, X_{i}^{\alpha}+\frac{1}{2} k_{2}\right)\right. \\
& \left.+\left|g\left(t_{i}+\frac{h}{2}, X_{i}^{\alpha}+\frac{1}{2} k_{2}\right)\right| \Phi^{-1}(\alpha)\right), \\
k_{4} & =h\left(f\left(t_{i}+h, X_{i}^{\alpha}+k_{3}\right)\right. \\
& \left.+\left|g\left(t_{i}+h, X_{i}^{\alpha}+k_{3}\right)\right| \Phi^{-1}(\alpha)\right) .
\end{aligned}
$$

For the proposed optimal control model of net risky capital asset with an uncertain differential equation

$$
\begin{aligned}
& d X(t) \\
& =[(\kappa+\beta) \psi-(\omega(\psi-1)+\mu+h-j-g)] X(t) d t \\
& \quad+\left[\psi \sigma_{p}+\psi \sigma_{b}-\sigma_{r}(\psi-1)\right] X(t) d C(t)
\end{aligned}
$$

with initial value $X_{0}$ and its $\alpha$-path equation.

$$
\begin{aligned}
& \text { i.e., } \\
& d X(t)^{\alpha} \\
& =[(\kappa+\beta) \psi-(\omega(\psi-1)+\mu+h-j-g)] X(t)^{\alpha} d t \\
& \quad+\left|\left[\psi \sigma_{p}+\psi \sigma_{b}-\sigma_{r}(\psi-1)\right] X(t)^{\alpha}\right| \Phi^{-1}(\alpha) d t .
\end{aligned}
$$

This is solved using the algorithm below.

\subsubsection{Algorithm 1: Runge-Kutta Method for Solving the Model}

Step 1. Given time interval $t,[a, b]$, iteration number $N$, and step length $h=(b-a) / N$, set $t_{i}=a+i h, i=0,1, \cdots, N$ and $\alpha>0$.

Step 2. Compute the corresponding differential equation

$$
\begin{aligned}
d X(t)^{\alpha}= & {[(\kappa+\beta) \psi-(\omega(\psi-1)+\mu+s-j-g)] } \\
& \cdot X(t)^{\alpha} d t \\
& +\left|\left[\psi \sigma_{p}+\psi \sigma_{b}-\sigma_{r}(\psi-1)\right] X(t)^{\alpha}\right| \frac{\sigma \sqrt{3}}{\pi} \\
& \cdot \ln \frac{\alpha}{1-\alpha} d t
\end{aligned}
$$

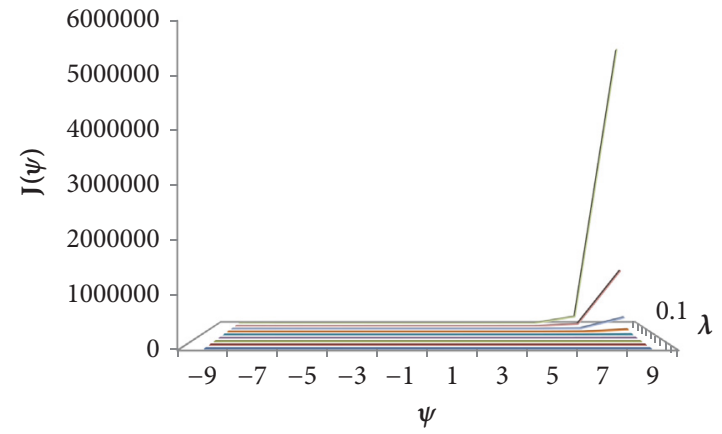

FIGURE 1: Graph of expected present value of the utility of asset $J(\psi)$ versus control $\psi$ and degree of relative risk $\lambda$ while subjective discount rate $\eta$ is fixed at 0.1 .

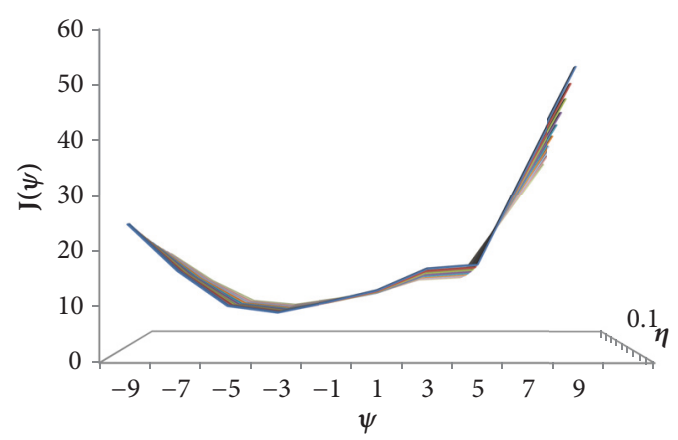

FIgURE 2: Graph of expected net value of the utility of asset $J(\psi)$ versus control $\psi$ and subjective discount rate $\eta$ while degree of relative risk $\lambda$ is fixed at 0.1 .

$X_{0}^{\alpha}=X_{0}$, with the Runge-Kutta method for solving uncertain differential equations.

Step 3. Set $i=i+1$, repeat Steps 2 and 3 for $N$ times, and then $X(t)^{\alpha}$ is derived. Go back to Step 1 until $t_{i}=b$.

Using Algorithm $1, X(t)^{\alpha}$ for every $\alpha$ can be computed.

A computer program in Maple 18 was used to implement the trapezoidal and fourth-order Runge-Kutta method for the uncertain differential equation on the uncertain optimal control problem.

Using the data in Tables 3 and 4, the numerical results to the asset-liability management problem is obtained and represented in Figures 1-11, thus illustrated in Tables 5 and 6.

4.4. Sensitivity Analysis. Here, the significance of some parameters included in the mathematical models is displayed using an optimal control model of the risky capital assets. The parameter sensitivity analysis was applied to the cost function and the constraint of the model to investigate the relative significance of each parameter.

4.4.1. Algorithm 2. The following algorithm is constructed for sensitizing the parameters in the optimal control problem:

(i) Select the parameters to be examined. 


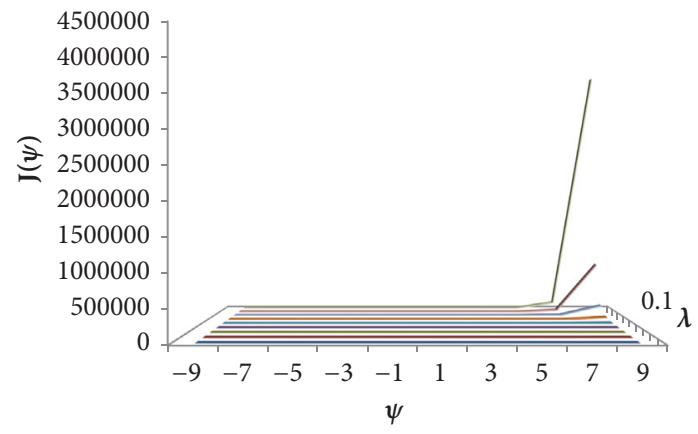

FIGURE 3: Graph of expected present value of the utility of asset $J(\psi)$ versus control $\psi$ and degree of relative risk $\lambda$ while subjective discount rate $\eta$ is fixed at 0.9 .

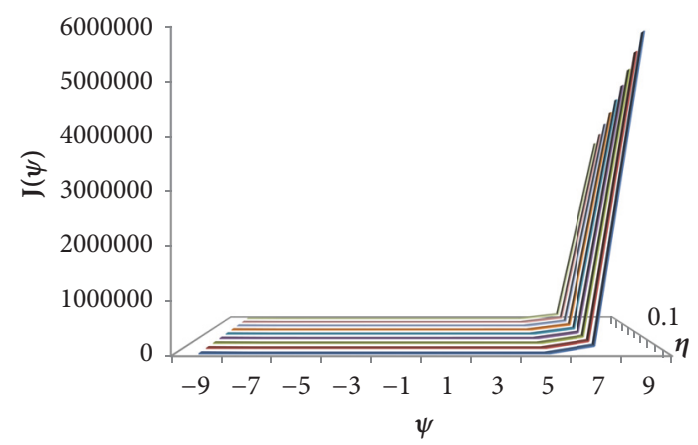

FIGURE 4: Graph of expected present value of the utility of asset $J(\psi)$ versus control $\psi$ and subjective discount rate $\eta$ while degree of relative risk $\lambda$ is fixed at 0.9 .

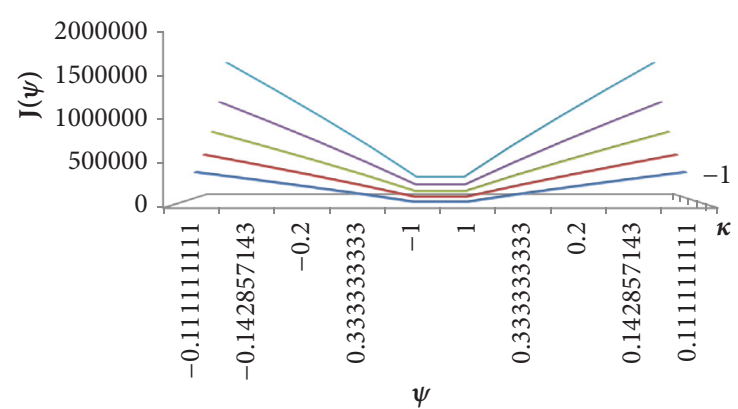

FIGURE 5: Graph of expected present value of the utility of asset $J(\psi)$ versus control $\psi$ and capital gain $\kappa$ while subjective discount rate $\eta$ and degree of relative risk $\lambda$ are fixed at 0.1 and 0.9 , respectively.

(ii) Assume values for each parameter.

(iii) Run the model using the selected series while keeping other parameters constant.

(iv) Calculate the objective function for each value of the asset performance.

(v) Find the percentage change in results and classify each parameter accordingly.

(vi) Evaluate parametric sensitivity, that is, group parameters on their level of sensitivity using graphical and tabular representations.

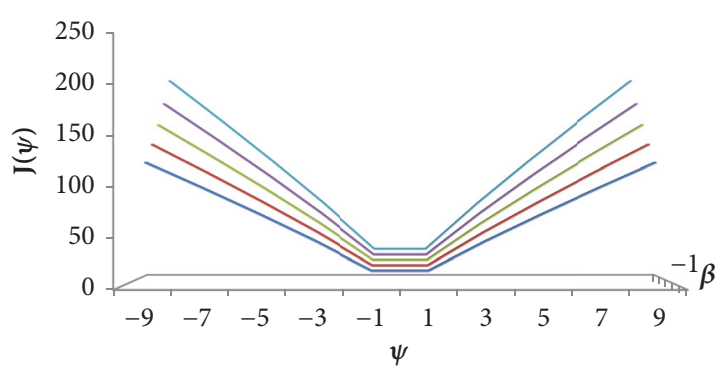

FIGURE 6: Graph of expected present value of the utility of asset $J(\psi)$ versus control $\psi$ and rate of return on capital asset $\beta$ while subjective discount rate $\eta$ and degree of relative risk $\lambda$ are fixed at 0.1 and 0.9 , respectively.

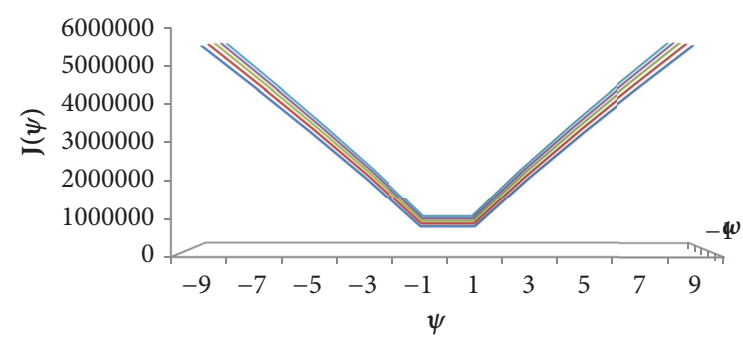

FIGURE 7: Graph of expected present value of the utility of asset $J(\psi)$ versus control $\psi$ and interest rate of liability $\omega$ while subjective discount rate $\eta$ and degree of relative risk $\lambda$ are fixed at 0.1 and 0.9 , respectively.

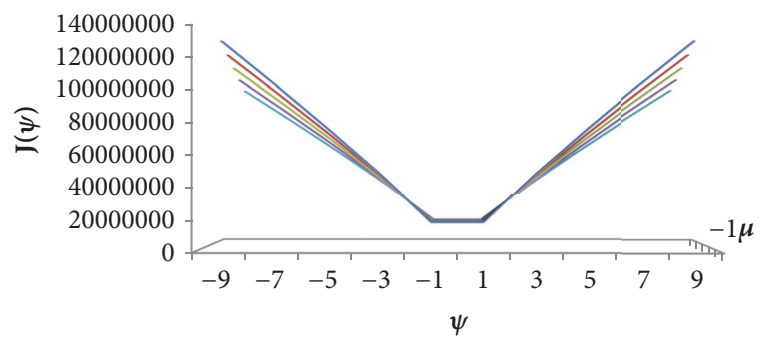

FIGURE 8: Graph of expected present value of the utility of asset $J(\psi)$ versus control $\psi$ and consumption level $\mu$ while subjective discount rate $\eta$ and degree of relative risk $\lambda$ are fixed at 0.1 and 0.9 , respectively. ter.

(vii) Determine the relative significance of each parame-

4.5. Parameter Estimation. To drive the application of the uncertain risky capital assets model so as to determine the sensitivity of the parameters, Algorithm 2 was implemented in Maple 18 presented in Figures 1-11 using the data available in Tables 1-2.

4.5.1. Graphical Representations of Sensitivity Analysis of Parameters to the Model. See Figures 1-11. 
TABLE 5: Effect of parameter estimations on model.

\begin{tabular}{|c|c|c|c|}
\hline Parameters & Average percentage change & Relative significance & Sensitivity \\
\hline$\lambda$ & $20 \%$ and above & $\begin{array}{l}\text { It is observed from Figures } 1 \text { and } 3 \text { that a little change in the value of } \lambda \\
\text { causes a huge change in the result of the model }\end{array}$ & Extremely sensitive \\
\hline$\eta$ & $5 \%$ & $\begin{array}{l}\text { It is observed from Figures } 2 \text { and } 4 \text { that a change in the value of } \eta \\
\text { causes a moderate change in the result of the model }\end{array}$ & Sensitive \\
\hline$\kappa$ & $42 \%$ & $\begin{array}{l}\text { It is observed that from Figure } 5 \text { that a little change in the value of } \kappa \\
\text { causes a huge change in the result of the model }\end{array}$ & Extremely sensitive \\
\hline$\beta$ & $15 \%$ & $\begin{array}{l}\text { It is observed from Figure } 6 \text { that a change in the value of } \beta \text { causes a } \\
\text { significant change in the result of the model }\end{array}$ & Very sensitive \\
\hline$\omega$ & $2 \%$ & $\begin{array}{l}\text { It is observed from Figure } 7 \text { that a change in the value of } \omega \text { causes a } \\
\text { moderate change in the result of the model }\end{array}$ & Sensitive \\
\hline$\mu$ & $6 \%$ & $\begin{array}{l}\text { It is observed from Figure } 8 \text { that a change in the value of } \mu \text { causes a } \\
\text { moderate change in the result of the model }\end{array}$ & Sensitive \\
\hline$s$ & $3 \%$ & $\begin{array}{l}\text { It is observed from Figure } 9 \text { that a change in the value of } s \text { causes a } \\
\text { moderate change in the result of the model }\end{array}$ & Sensitive \\
\hline$j$ & $0.3 \%$ & $\begin{array}{c}\text { It is observed from Figure } 10 \text { that a change in the value of } j \text { causes an } \\
\text { insignificant change in the result of the model }\end{array}$ & Insensitive \\
\hline$g$ & $0.2 \%$ & $\begin{array}{c}\text { It is observed from Figure } 11 \text { that a change in the value of } g \text { causes an } \\
\text { insignificant change in the result of the model }\end{array}$ & Insensitive \\
\hline
\end{tabular}

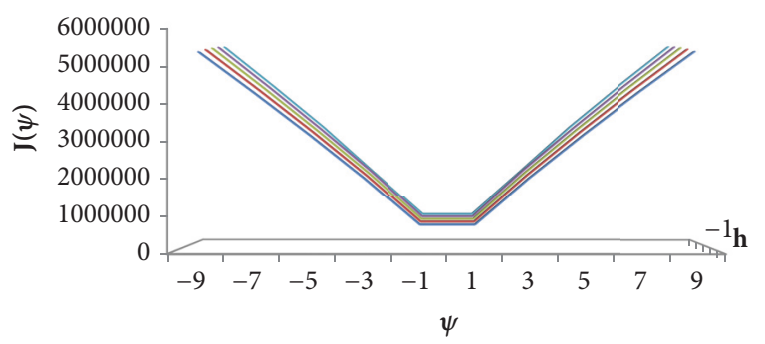

FIGURE 9: Graph of expected present value of the utility of asset $J(\psi)$ versus control $\psi$ and asset supply ratio $s$ while subjective discount rate $\eta$ and degree of relative risk $\lambda$ are fixed at 0.1 and 0.9, respectively.

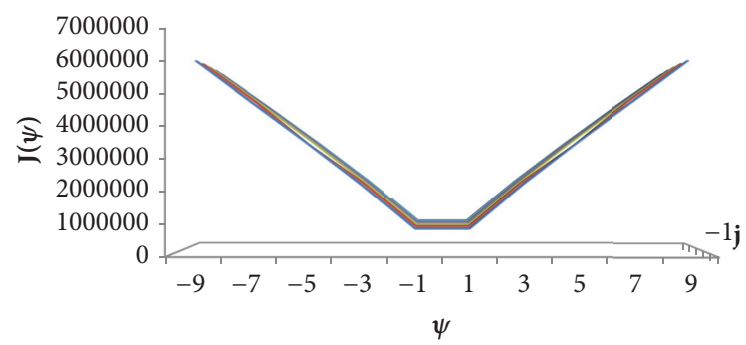

FIGURE 10: Graph of expected present value of the utility of asset $J(\psi)$ versus control $\psi$ and tax ratio $j$ while subjective discount rate $\eta$ and degree of relative risk $\lambda$ are fixed at 0.1 and 0.9 , respectively.

\section{Discussion on Results}

From Figures 1-11, it is easy to classify the selected parameters with respect to their level of sensitivity and relative significance.
TABLE 6: Execution time for solving model.

\begin{tabular}{lcc}
\hline Model & Result & Time $(\mathrm{s})$ \\
\hline Original & $5.962 \times 10^{6}$ & 9.625 \\
Modified & $6.055 \times 10^{6}$ & 8.112 \\
$\%$ change & $2 \%$ & $16 \%$ \\
\hline
\end{tabular}

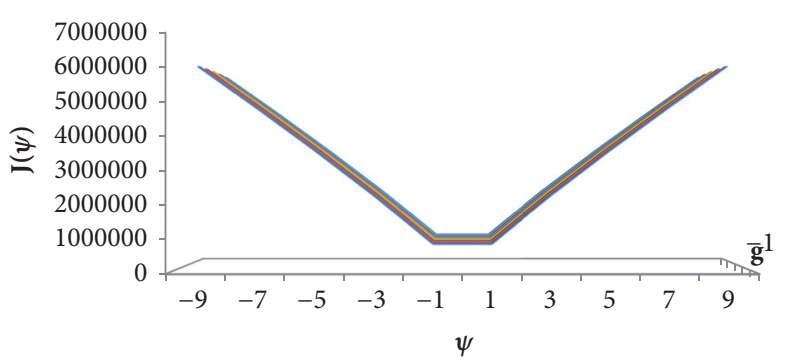

FIGURE 11: Graph of expected present value of the utility of asset $J(\psi)$ versus control $\psi$ and depreciation ratio $g$ while subjective discount rate $\eta$ and degree of relative risk $\lambda$ are fixed at 0.1 and 0.9 , respectively.

Furthermore, the sensitivity of the parameters in the model shows that the higher the degree of relative risk $\lambda$, the higher the expected present value of the utility of asset which implies that the more the investor is willing to take more risk in investing in capital assets, the higher the expectation of his or her business' net worth is.

It is also observed that both parameters in the objective functional of the model are of relative significance such that they can both be classified as sensitive parameters but the change in the parameter $\lambda$ has a huge effect on the result compared to that of parameter $\eta$. 
Therefore, the optimal expected present value of the utility of asset using the debt profile of Nigeria as a study case are derived at the minimum point of $\eta$ and maximum point of $\lambda$ (that is, where $\eta=0.1$ and $\lambda=0.9$ ).

However, based on the classification of sensitivity discussed above, it is concluded that the parameters of tax ratio $j$ and depreciation ratio $g$ are insensitive such that their presence in the model formulation can be ignored as their influence on the model's result is not critical. This can explain why Stein [6] did not introduce the input factors of tax ratio $j$ and depreciation ratio $g$ in his model formulation. The removal of the insensitive parameters results in the modified model as

$$
J(\psi)=\min _{\psi} E_{C}\left[\int_{t_{0}}^{t_{n}} \frac{1}{\lambda} e^{-\eta t}(\psi X(t))^{\lambda} d t\right]
$$

subject to

$$
\begin{aligned}
d X(t)= & {[(\kappa+\beta) \psi-(\omega(\psi-1)+\mu+s)] X(t) d t } \\
& +\left[\psi \sigma_{p}+\psi \sigma_{b}-\sigma_{r}(\psi-1)\right] X(t) d C(t)
\end{aligned}
$$

The execution time was derived from Maple18 software on a Hp Elitebook 8460p with processor Intel ${ }^{\circledR}$ Core $^{\mathrm{TM}}$ i72620 CPU @ 2.70GHz, 4.00GB RAM, and 64-bit Operating System.

Effect of this modification on the computational process, as shown in Table 6 , was a change of approximately $2 \%$ in the result of the model and a reduction of approximately $16 \%$ in the execution time.

\section{Conclusion}

Capital asset management as a real-life endeavour needs to be studied as a multidisciplinary subject making use of contributions from the relevant fields. As shown in this work, mathematics has a lot to contribute as well as improve on its advancement. Analysis of sensitivity of parameters included in models obtained for real-life problems is herein shown to be a worthwhile task of refining the model not only to optimize the model results and help decision-making but also to maximize the computational efforts and the time required in dealing with asset management system. Likewise, the notion of mathematical modelling has been utilized to study the problem of capital asset management with a view to propose a solution by driving some control policies to evaluate and monitor asset management problems. Furthermore, realization of expected present value of the utility of asset based on the perspectives of individuals, stakeholders, or regulators other than that of investors can be considered in future works. However, the result from this work is applicable to private or public investors where relative importance of input parameters in managing capital assets is determined.

\section{Data Availability}

The Nigeria net worth profile data used to support the findings of this study are included within the article and are also available at the World Bank website (data.worldbank.org/indicator), Debt Management Office of Nigeria website (https://www.dmo.gov.ng/), and National Bureau of Statistics website (nigerianstat.gov.ng).

\section{Conflicts of Interest}

The authors declare that they have no conflicts of interest.

\section{References}

[1] J. E. Mazur, "Mathematical Models and the Experimental Analysis of Behaviour," Journal of the Experimental Analysis pf Behaviour, vol. 85, no. 2, pp. 275-291, 2006.

[2] S. S. Rao, Engineering Optimization: Theory and Practice, John Wiley and Sons, Fourth edition, 2009.

[3] R. C. Merton, "Optimum consumption and portfolio rules in a continuous-time model," Journal of Economic Theory, vol. 42, no. 3, pp. 373-413, 1971.

[4] Y. Zhu, "Uncertain optimal control with application to a portfolio selection model," Cybernetics and Systems, vol. 41, no. 7, pp. 535-547, 2010.

[5] L. Deng and Y. Zhu, "An uncertain optimal control model with n jumps and application," Computer Science and Information Systems, vol. 9, no. 4, pp. 1453-1468, 2012.

[6] J. L. Stein, "Stochastic optimal control modelling of debt crises," CESifo (Working Paper, vol. 1043, p. 23, 2003.

[7] D. Edwards and M. Hamson, Guide to Mathematical Modelling, Macmillan Press Limited, London, UK, 1989.

[8] R. T. Ashleigh, N. F. David, and M. Sharmistha, "Using mathematical models to inform syphilis control strategies," $B M C$ Public Health, vol. 13, no. 606, 2013.

[9] B. O. Oyelami and A. A. Asere, "Mathematical modelling: An application to corrosion in a petroleum industry," in National Mathematical Centre, pp. 48-56, National Mathematical Centre, Abuja Nigeria, 2009.

[10] M. Poller and S. Achilles, "Aggregated wind park models for analyzing power system dynamics," in Proceedings of the in Proceedings of the 4th International Workshop on LargeScale Integration of Wind Power and Transmission Networks for Offshore Windfarms, Billund, Denmark, 2003.

[11] G. Ajmone Marsan, N. Bellomo, and M. Egidi, "Towards a mathematical theory of complex socio-economical systems by functional subsystems representation," Kinetic and Related Models, vol. 1, no. 2, pp. 249-278, 2008.

[12] S. Rosa and D. F. Torres, "Parameter estimation, sensitivity analysis and optimal control of a periodic epidemic model with application to HRSV in Florida," Statistics, Optimization \& Information Computing, vol. 6, no. 1, pp. 139-149, 2018.

[13] N. S. Papageorgiou, V. D. Radulescu, and Repovs D. D., "Sensitivity analysis of optimal control problems goverened by nonlinear evolution inclusions," Advances in Nonlinear Analysis, vol. 6, no. 2, pp. 199-235, 2017.

[14] P. Kathirgamanathan and T. Neitzart, "Optimal control parameter estimation in aluminum extrusion for given product characteristics," in Proceedings of the world Congress in Engineering, p. 1, London, II, 2008.

[15] S. Guo, Y. Liu, X. Guo, and L. Zuo, "Performance evaluation and parameter sensitivity of energy-haarvesting shock absorbers on different vehicles," International Journal of Vehicle Mechanics and Mobility, vol. 7, 45. 
[16] T. H. Christopher and A. R. Fathalla, "Sensitivity analysis of parameters in modelling with delay-differential equations," Manchester Center for Computational Mathematics, Numerical Analysis Reports, 180-199.

[17] J. A. Burns, E. M. Cliff, and S. E. Doughty, "Sensitivity analysis and parameter estimation for a model of chlamydia trachomatis infection," Gruyter, pp. 19-32, 2007.

[18] L. A. Bastidas, J. Knighton, and S. W. Kline, "Parameter sensitivity and uncertainty analysis for a storm surge and wave model," Natural Hazards and Earth System Sciences, vol. 16, no. 10, pp. 2195-2210, 2016.

[19] P. Tunjo and B. Zoran, "Financial structure optimization by using goal programming approach," Croatian Operational Research Review, vol. 3, no. 1, pp. 150-162, 2012.

[20] X. Huang, "Portfolio selection with a new definition of risk," European Journal of Operational Research, vol. 186, no. 1, pp. 351357, 2008.

[21] M. Schyns, Modelling financial data and portfolio optimization problems [Doctoral Dissertation], 2001, http://orbi.ulg.ac.be/bitstream/MSthese.

[22] B. D. Liu, Uncertainty Theory, Springer, Berlin, Germany, 2nd edition, 2007.

[23] T. Latunde and O. M. Bamigbola, "Uncertain optimal control model for management of net risky capital asset," IOSR Journal of Mathematics, vol. 12, no. 3, pp. 22-30, 2016.

[24] X. Yang and Y. Shen, "Runge-Kutta Method for Solving Uncertain Differential Equations," Journal of Uncertainty Analysis and Applications, vol. 3, no. 1, 2015. 


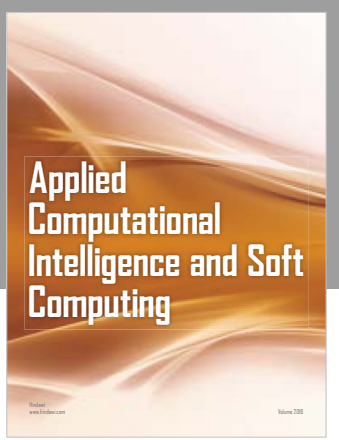

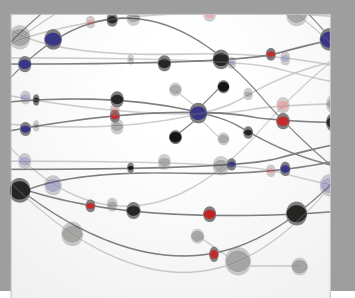

The Scientific World Journal
Submit your manuscripts at

Computing
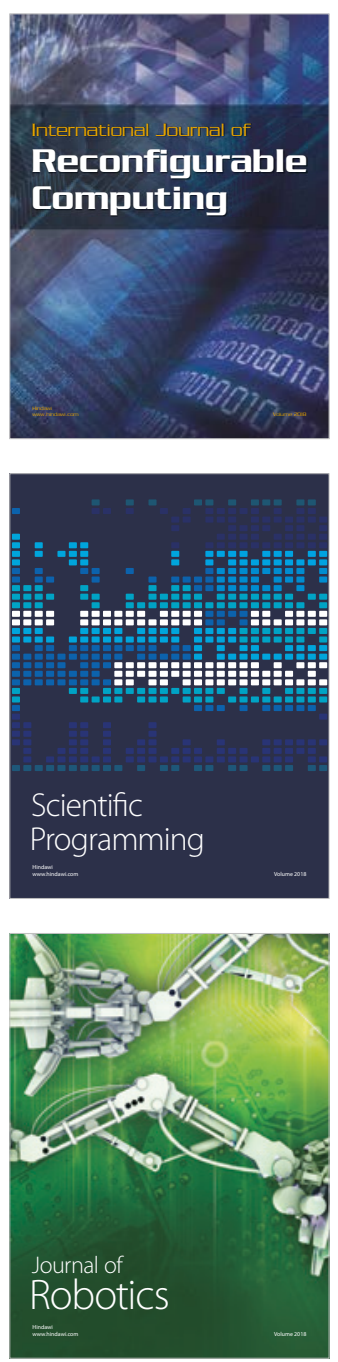

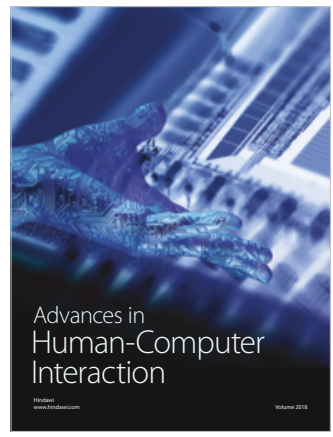

Human-Compute

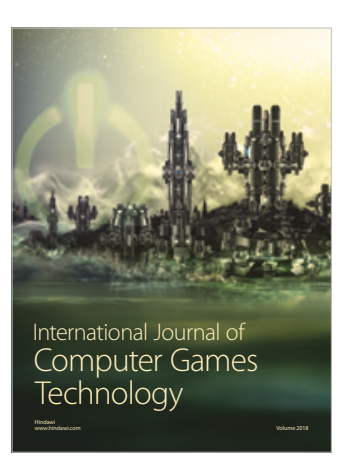

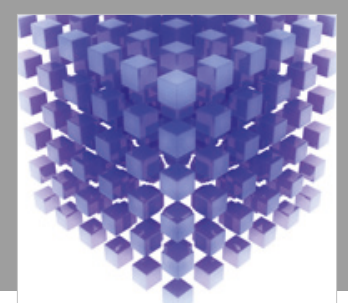

Mathematical Problems in Engineering

\section{Engincering}
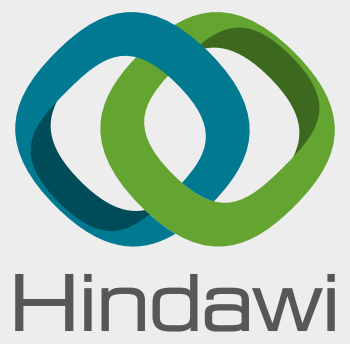

www.hindawi.com
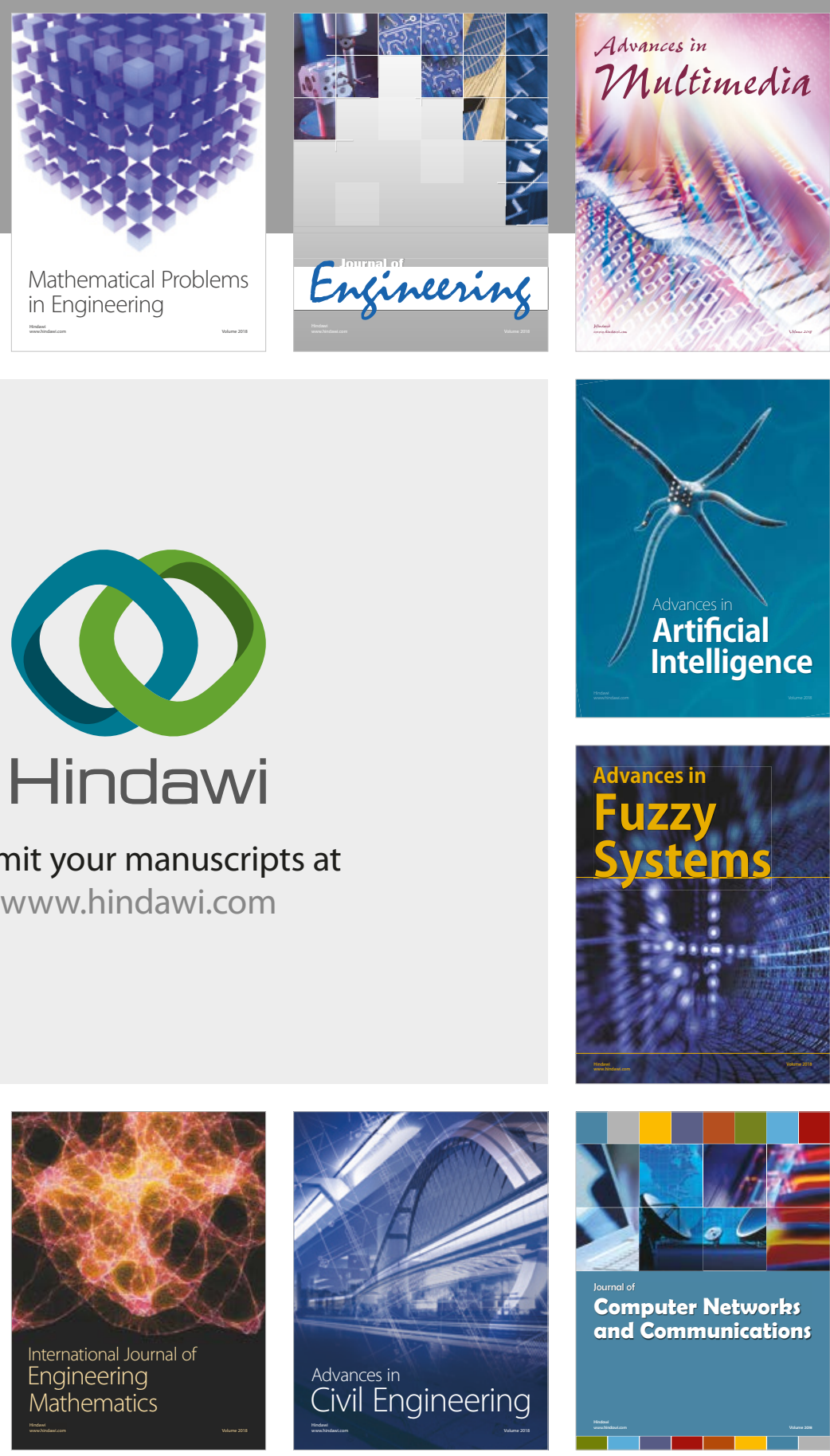

Computer Networks and Communications

Multimedia
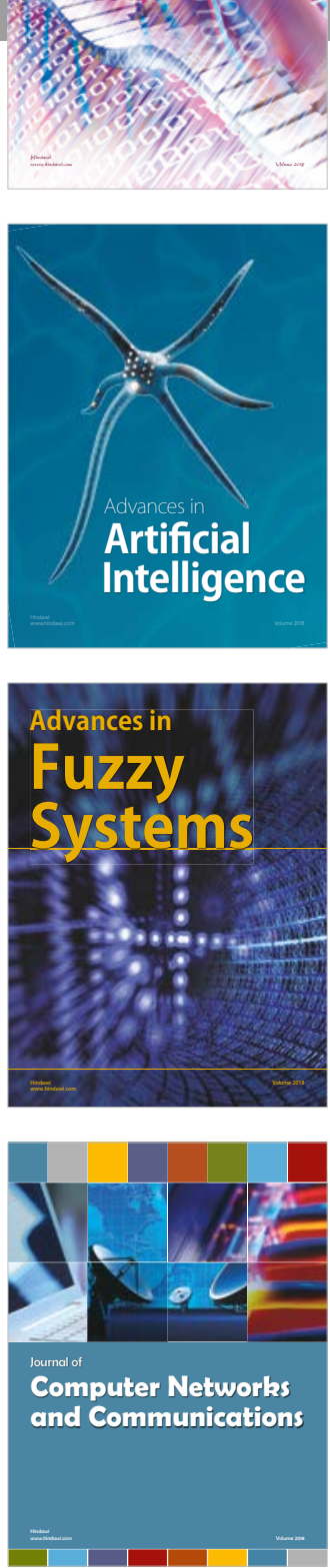

Advances in

Modelling \&

Simulation

in Engineering

interaction

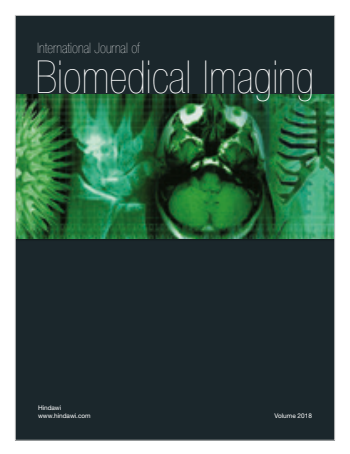

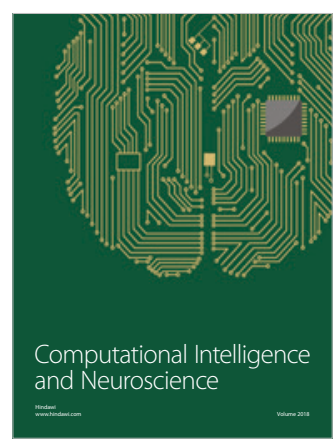

